Published in final edited form as:

Gastrointest Endosc. 2015 August ; 82(2): 246-255. doi:10.1016/j.gie.2015.03.1974.

\title{
Assessment of mucosal healing in inflammatory bowel disease
}

\author{
Parambir S. Dulai, MBBS ${ }^{1,2}$, Barrett G. Levesque, MD, MS $^{1,2}$, Brian G. Feagan, MD $^{2,3}$, Geert \\ D’Haens, MD, PhD ${ }^{2,4}$, William J. Sandborn, MD ${ }^{1,2}$
}

\author{
1.University of California San Diego, San Diego, CA ${ }^{2}$ Robarts Clinical Trials, Robarts Research \\ Institute, Western University, London, Ontario, Canada ${ }^{3}$.Department of Medicine, Western \\ University, London, Ontario, Canada 4.Department of Gastroenterology, Academic Medical \\ Center, Amsterdam, The Netherlands
}

\begin{abstract}
Background: Mucosal healing (MH) is an important treatment end-point in inflammatory bowel disease (IBD), and achieving MH has been demonstrated to improve disease related outcomes. Considerable uncertainty exists however, regarding the optimal approach for the assessment of MH.
\end{abstract}

\begin{abstract}
Aims: Compare currently available diagnostic tools for the assessment of $\mathrm{MH}$, and outline the ideal approach to integrating these tools into clinical trials and clinical practice.

Methods: Review article

Results: Endoscopy represents the gold standard for the assessment of $\mathrm{MH}$, and frequent endoscopic assessment is associated with a higher rate of achieving MH. The use of mucosal biopsy allows for the identification of persistent histologic disease activity, but the incremental clinical benefit of achieving histologic healing is yet to be determined. Magnetic resonance enterography (MRE) has a high sensitivity for ulcer healing in endoscopically inaccessible disease activity. However, the presence of mucosal lesions cannot be reliably excluded based on this
\end{abstract}

Corresponding Author: William J. Sandborn, MD, University of California, San Diego, 9500 Gilman Drive, MC 0956 La Jolla, CA 92093, wsandborn@ucsd.edu, Tel: 858-657-5284 Fax: 858-657-5022.

Potential Conflicts and Disclosures: PSD has received research support from Alpco and Polymedco. BGL has served as a consultant for Takeda, Abbvie, and Nestle health sciences. BGF has received research support from, participated on scientific advisory boards, and served as a consultant for Abbott/Abbvie, Amgen, Astra Zeneca, Bristol-Myers Squibb, Janssen, Pfizer, Tillotts, and UCB Pharma; has participated on scientific advisory boards and served as a consultant for Avaxia Biologics Inc., Celgene, Biogen, Ferring, Merck, Novonordisk, Prometheus, Protagonist, Salix, Takeda, TiGenix, and Teva; has received research support and served as a consultant for Roche/Genentech, Millennium, and Receptos; has received research support from Santarus and Sanofi; has served on scientific advisory boards for Novartis, has served as a consultant forActogenix, Albireo Pharma, Avir Pharma, Axcan, Baxter Healthcare Corp., Boehringer-Ingelheim, Calypso Biotech, EnGene, , GiCare Pharma, Gilead, Given Imaging Inc., GSK, Ironwood Pharma, Kyowa Kakko Kirin Co Ltd., Lexicon, Lilly, Nektar, Serono, Shire, Sigmoid Pharma, Synergy Pharma Inc., Vertex Pharma, VHsquared Ltd., Warner-Chilcott, Wyeth, Zealand, Zyngenia; has participated in speakers bureaus for Abbott/AbbVie, JnJ/Janssen, Takeda, Warner-Chilcott, UCB Pharma; and is on the board of directors for Robarts Clinical Trials. GDH has received research support and lecture fees from, and served as a consultant for Abbvie, Janssen and Takeda; has served as a consultant for and received lecture fees from Centocor, Ferring, Giuliani SpA, Merck, Otsuka, Shire, Schering-Plough, Tillotts, UCB, and Vifor; has received research support from Given Imaging, MSD, DrFalk Pharma, and Photopill; has served as a consultant for Ablynx, ActoGeniX, AM Pharma, Boehringer Ingelheim GmbH, ChemoCentryx, Cosmo Technologies, Elan Pharmaceuticals, Engene, Dr Falk Pharma, Galapagos, Given Imaging, GlaxoSmithKline, Mitsubishi Tanabe Pharma, Neovacs, Novonordisk, PDL Biopharma, Pfizer, Receptos, Salix, Sandoz, Setpoint, Sigma, Versant; and has received lecture fees from Norgine, and Tramedico. WJS has received research support from Janssen, Abbvie, and Western University London Ontario (owner of Robarts Clinical Trials); and has served as a consultant for Janssen, Abbvie, UCB Pharma, Shire, Salix, and Takeda 
modality alone and further small bowel endoscopy should be considered in symptomatic patients. Video capsule endoscopy (VCE) or device assisted enteroscopy (DAE) can be used, with DAE being preferred in stricturing Crohn's disease due to the risk of capsule retention, or in patients where small bowel malignancy is a possibility.

Conclusions: Endoscopy remains the gold standard for the assessment of MH. Several alternative diagnostic modalities have become available that can be of value in specific clinical circumstances, particularly in patients with small bowel involvement.

\section{Introduction}

Ulcerative colitis (UC) and Crohn's disease (CD) are idiopathic inflammatory bowel diseases (IBD) characterized by recurrent episodes of intestinal inflammation and mucosal ulceration. ${ }^{1-3}$ Management strategies have traditionally been aimed at the non-specific inhibition of inflammation with the intent of reducing disease related symptoms, such as diarrhea, abdominal pain, and fatigue. Accordingly, treatment end-points have largely focused on subjective measures of symptom severity. ${ }^{4}$ Symptom based measures however, correlate poorly with mucosal inflammation, are difficult to apply in clinical practice, and have little value in predicting disease related morbidity and mortality. ${ }^{5-8}$ Recent advances in biologic therapy have transitioned treatment goals towards targeting specific inflammatory mechanisms with the intent of modifying long-term outcomes such as disease related complications, hospitalizations and surgery. Thus, efforts have now focused on identifying well-defined, reliable, and readily measurable end-points that accurately predict treatment response and long-term outcomes. ${ }^{6}$

Central to the pathogenesis of IBD is mucosal barrier dysfunction, which leads to an aberrant host response to commensal microorganisms, and ultimately, loss of intestinal immune homeostasis. The end result of this uncontrolled immune reaction is intestinal inflammation, erosions, friability and mucosal ulceration. ${ }^{1-3}$ Thus, restoration of barrier function through mucosal healing $(\mathrm{MH})$ has the potential to be a key treatment target in IBD. In support of this concept data from both clinical trials and prospective cohort studies have demonstrated that the presence of $\mathrm{MH}$ following treatment is associated with better short and long-term disease related outcomes. ${ }^{9-11}$ The optimal approach to assessing and integrating this new treatment target into clinical practice remains to be determined. In this review we will highlight the modalities currently available for the assessment of $\mathrm{MH}$, and outline a pragmatic approach to integrating these tools into clinical practice. We anticipate this will allow providers to better understand the changing role of MH in IBD and the optimal approach to utilizing this end-point in clinical practice.

\section{Mucosal healing: Clinical relevance and current definitions}

A fundamental principle regarding the importance of $\mathrm{MH}$ as a treatment target for IBD is that restoration of mucosal integrity is critical to re-establishing the barrier function of gut epithelium. An intact mucosal barrier prevents the translocation of commensal bacteria into the mucosa and submucosa, thereby down-regulating the pathological immune response, which in turn, ameliorates clinical manifestations of the disease. ${ }^{11}$ Although symptom-based metrics such as resolution of pain, bleeding and diarrhea hypothetically might be adequate 
surrogates for $\mathrm{MH}$, a strong correlation has not been demonstrated between these methods of assessment. ${ }^{5,6,12,13}$ A key feature of IBD is the repetitive nature in which epithelial damage occurs, often before clinical signs manifest. ${ }^{14,15}$ Thus, the chronicity of damage is often well established at the time of presentation, and healing often lags behind symptomatic improvement. ${ }^{5}$ Logically this would suggest that symptom based assessments may be neither sensitive nor specific enough, when used in isolation, to adequately manage patients. Given the clinical impact of continued mucosal inflammation on short and long-term disease related complications, and the clear impact improving endoscopic disease activity and achieving MH has on reducing these risks, ${ }^{16-22}$ (Table 1) an impetus has developed to include $\mathrm{MH}$ as a primary treatment target in both clinical trials and clinical practice. ${ }^{6}$

The greatest experience with the use of $\mathrm{MH}$ as a treatment target has been in the setting of randomized controlled trials. (Table 2) Within these trials however, definitions have varied considerably for both UC and CD. Hence, it is not surprising that no well validated and widely accepted definitions exist in clinical practice. This deficiency has created considerable uncertainty regarding the optimal approach to integrating $\mathrm{MH}$ as a treatment target. ${ }^{12,13,23}$ In UC, disease activity is limited to the mucosa and thus it seems plausible that $\mathrm{MH}$ represents the ultimate therapeutic goal. Therefore, absence of friability, blood, erosions, or ulcerations in all examined segments with restoration of a normal vascular pattern seems to be a valid definition. ${ }^{7}$ The definition of $\mathrm{MH}$ in $\mathrm{CD}$ is less easily defined given the transmural nature of the disease and wide variability in lesion characteristics. The International Organization for Inflammatory Bowel Disease has proposed defining $\mathrm{MH}$ in $\mathrm{CD}$ as the absence of all visible ulcers. ${ }^{8}$ Although this dichotomous definition is simple to apply in clinical practice, it is relatively insensitive to change, and does not allow for a quantification of overall improvement or improvement beyond ulcer healing. It is important though to recognize that the importance of 'complete' MH beyond healing of ulcerations and erosions is yet to be determined. ${ }^{24}$ Accordingly, for practical purposes, providers should consider the term MH to represent the absence of friability (UC), ulcerations, and erosions (UC and CD).

\section{Performance characteristics of available diagnostic tools Endoscopy}

Endoscopy plays an integral role in the diagnosis, monitoring and management of IBD and IBD related complications. One of the most important roles for endoscopy remains its ability to assess and stratify disease activity, which in turn influences medical decisions. ${ }^{25,}{ }^{26}$ In the past few years this role has been given greater prominence, and a new role has emerged in the assessment and monitoring of treatment response. ${ }^{27-29}$ Despite the overall willingness of patients to undergo repeated assessment, ileocolonoscopy is not inexpensive, it places patients at risk for complications, and its use can be limited by resource constraints.

Therefore, it is important to identify an optimal approach for utilizing this diagnostic tool in an effort to maximize its clinical value. ${ }^{30-32}$

Feasibility and frequency of endoscopic assessment-Although MH is a wellestablished outcome measure in clinical trials, ${ }^{5,33-48}$ data regarding its use as a treatment 
target in clinical practice is limited. A recent retrospective cohort study, performed at a single institution, evaluated the practicality of treating to the target of $\mathrm{MH}$ in $67 \mathrm{CD}$ patients.

${ }^{28}$ Patients underwent repeated endoscopy assessment of disease activity at a median interval of 24 weeks (Interquartile range [IQR] 17 - 38). At the end of 62 weeks (IQR 44-79) of follow-up, 34 (51\%) patients had achieved $\mathrm{MH}$ and the only factors associated with achieving MH were fewer than 26 weeks between initiation of treatment and time of endoscopy (hazard ratio [HR] 2.35, 95\% confidence interval [CI] 1.15 - 4.97, $p=0.019$ ), and adjustment of medical therapy when MH was not observed on endoscopy (HR 4.28, 95\% CI $1.9-11.5, p<0.001)$. A similar study in UC, which evaluated 60 patients who underwent at least 2 consecutive endoscopic assessments of disease activity, demonstrated that repeated endoscopic assessment was feasible and treatment adjustment based on endoscopy improved the likelihood of achieving MH. ${ }^{29}$ These two studies demonstrate the feasibility of using endoscopy for the assessment of $\mathrm{MH}$ in clinical practice, and suggest that re-evaluation within a minimum of 24 weeks is necessary for success. However, these concepts still require additional validation in larger, more methodologically rigorous studies. REACT 2 is a cluster randomization trial in which approximately 40 international gastroenterology practices and $1200 \mathrm{CD}$ patients will be randomized to either an enhanced care algorithm group, with treatment intensification guided by endoscopic assessment, or a conventional step-up care algorithm. The primary outcome measure of the study is the risk of CD related complications over the entire follow-up period. ${ }^{49}$

Operating properties of endoscopic indices-Several endoscopic indices from clinical trials are available for use in clinical practice. ${ }^{12,13}$ (Table 3) The two endoscopic indices most widely used and studied for CD are the Crohn's disease endoscopic index of severity (CDEIS) and the Simplified endoscopic score in Crohn's disease (SES-CD). The CDEIS is a complex scoring system where various descriptors (deep and superficial ulcerations, ulcerated or non-ulcerated stenosis) are combined with the average extent of diseased and ulcerated mucosa. Although the CDEIS allows for a complete and detailed examination of disease activity, the index has fair interobserver agreement for grading of superficial (intraclass correlation coefficient [ICC] 0.63 - 0.77) and deep ulcerations (ICC $0.67-1.00) .{ }^{12}$ The SES-CD, a simplified version of the CDEIS, has demonstrated a high degree of correlation with the CDEIS for grading of disease activity (Pearson correlation coefficient $0.89,95 \%$ CI, $0.84-0.92$; Spearman rank coefficient $0.91,95 \%$ CI, $0.87-0.94$, $p<0.001$ ) and responsiveness to changes in disease activity (Pearson's $\mathrm{r}=0.89, p<0.001$ ), with similar intra- and interobserver agreement. ${ }^{12}$ (Table 3 ) Therefore, the simplicity of use and high degree of correlation with the CDEIS, make the SES-CD a favorable diagnostic index for use in clinical practice.

Within UC, the most widely used endoscopic index is the Mayo endoscopic score. (Table 3) This endoscopic index is simple to apply in routine practice, and the agreement among central readers has varied with some studies demonstrating a high level of agreement (Intraobserver: ICC 0.89, 95\%CI 0.85 - 0.92; Interobserver: ICC 0.79, 95\% CI $0.72-0.95$ ), 13 and others suggesting only a fair to moderate level of agreement (Interobserver Kappa $0.38,95 \% \mathrm{CI} 0.33-0.43) .{ }^{50}$ Given its inability to account for global severity, and the simplicity of scoring (0-3 points), concerns arise regarding its ability to accurately quantify 
treatment response over time. In an effort to overcome this, an alternative index, the Ulcerative Colitis Endoscopic Index of Severity (UCEIS) has been developed which take into account a more detailed assessment of disease activity.

The UCEIS was developed based on a formal validation program, and takes into account a more detailed scoring system for key sub-components with the least amount of variability among readers (vascular pattern, bleeding, and erosions/ulcerations). This 8 point scoring index has demonstrated excellent intra- and interobserver agreement among central readers (intraobserver: ICC 0.89, 95\% CI $0.85-0.93$; interobserver: ICC $0.83,95 \%$ CI $0.77-0.88$ ), 51 and offers the advantage of a more detailed assessment for key sub-components as compared to the Mayo score. The UCEIS can easily be translated into clinical practice for monitoring treatment effect, and is likely to become the endoscopic index of choice for this purpose.

Potential value of histologic disease activity assessment-Given the complex molecular process involved in restoring intestinal barrier function, some authors have suggested that histologic healing should be incorporated into the existing definitions of $\mathrm{MH}$. 11, 52 The incremental benefit of achieving histologic healing beyond that of endoscopic $\mathrm{MH}$ in UC has been suggested, but the validity of current histologic scoring systems for this purpose has not been established. ${ }^{53}$ Little is known about histologic healing in CD. Recognizing that the definition of MH is evolving, and the prognostic value of histologic healing in IBD is being actively studied, great potential exists for the use of histology as a treatment target. ${ }^{54}$ Thus, it is important to understand how recent innovations in endoscopic imaging techniques may influence our ability to assess histologically defined activity. 55,56

Recent studies have shown that angiogenesis plays an important role in the pathogenesis of IBD, and therefore monitoring of the mucosal vascular pattern might identify early or residual disease activity in otherwise normal appearing mucosa. ${ }^{56,57}$ There are two principal mechanisms through which providers may enhance endoscopic visualization of the mucosal vascular pattern. The first, dye based chromoendoscopy, is a technique wherein a dye (i.e. methylene blue or indigo carmine) is sprayed on the mucosal surface at the time of endoscopy. The second, dye-less chromoendoscopy, utilizes high-contrast imaging to enhance mucosal details. This technique is based upon capturing varying wavelengths of reflected light (optical chromoendoscopy, i.e. narrow band imaging (NBI); Olympus, Japan), or through digital post-processing of the endoscopic images (digital chromoendoscopy, i.e. Iscan; Pentax, Japan). The dye-less chromoendoscopy techniques are less effective for IBD dysplasia surveillance when compared to dye based chromoendoscopy, but they offer the advantage of being able to switch from conventional white light endoscopy to dye-less chromoendoscopy with the push of a button. ${ }^{58}$ The exact role of dye-less chromoendoscopy for IBD disease activity monitoring is yet to be established.

In a pilot study of 14 IBD patients, Danese et al. ${ }^{59}$ demonstrated that the use optical chromoendoscopy (NBI) detected increased angiogenesis in areas that appeared normal with white light endoscopy. Kudo et al. ${ }^{60}$ similarly demonstrated that, although white light endoscopy was feasible for detecting the presence of a distorted vascular pattern, the evaluation of mucosal vascular pattern with NBI yielded a much more precise determination 
of acute microscopic inflammation in patients with otherwise clinically and endoscopically quiescent disease activity. A randomized double-blind control study was recently conducted in 78 IBD patients comparing high definition white light endoscopy to computed virtual chromoendoscopy. Within this study, the use of digital chromoendoscopy did not significantly increase the overall duration of the procedure, but it did significantly improve the characterization of mucosal inflammation extent and severity $(p<0.001){ }^{61}$

In summary these newer techniques have the potential to improve the real time evaluation of disease activity, however the clinical utility of this technology has not been rigorously studied and must be established before these modalities are incorporated into routine practice. $^{62}$

\section{Magnetic resonance enterography}

Cross sectional imaging is important in $\mathrm{CD}$ for evaluating disease severity, determining extent of involvement, and diagnosing complications, such as strictures, fistulas and abscesses. Given the strong correlation between inflammatory activity on imaging and endoscopy, and the fact that a sub-set of CD patients have isolated small bowel disease that is beyond the reach of ileocolonoscopy, investigators have begun to consider the potential application of repeated cross sectional imaging for monitoring treatment response. ${ }^{63,64}$ Computerized tomography enterography (CTE) and magnetic resonance enterography (MRE) are currently used in clinical practice, and the diagnostic effectiveness of these imaging tools is similar. The exposure to ionizing radiation with CTE however, constrains its application for the repeated assessment of disease activity and MH. ${ }^{65,66}$

Initial studies investigating the value of MRE in monitoring disease activity and treatment response showed inconsistent results. Some investigators demonstrated a significant correlation between MRE signal intensity and treatment response, ${ }^{67}$ while others found that, although significant improvements in MRE findings occurred, normalization of findings with treatment was rare despite meaningful changes in clinical disease activity. ${ }^{68}$ This raised concerns that MRE might be overly sensitive, and MRE guided therapy could result in unnecessary adjustments in treatment. A recent prospective multicenter study by Ordas et al. 23 aimed to specifically address this question by defining the operating properties of MRE in CD.

Forty eight patients with CDEIS scores $\geq 7$ and ulcers in at least one intestinal segment, were enrolled to undergo MRE and ileocolonoscopy at baseline, and 12 weeks after completing treatment with corticosteroids or tumor necrosis factor (TNF) antagonists. Patients were evaluated by MRE using the MaRIA score, with ulcer healing and MH being defined as scores of $<11$ and $<7$, respectively. ${ }^{69}$ Half of the patients achieved endoscopic ulcer healing and $\mathrm{MH}$ (defined as CDEIS < 3.5) at week 12, and the correlation between the CDEIS and MaRIA score was highly significant $(r=0.81, p<0.001)$. The MaRIA score was also demonstrated to be highly responsive to treatment effect (standardized effect ratio 1.72, standard effect $>0.8$ meaning a large effect of responsiveness for an evaluative instrument). Although the sensitivity of the scoring tool for ulcer healing (94\%) was high, the specificity $(69 \%)$ and negative predictive value $(67 \%)$ was low. Similarly, the sensitivity (85\%), specificity $(78 \%)$, and negative predictive value $(63 \%)$ for MH (CDEIS < 3.5), was less than 
ideal. Thus, MRE may suggest active inflammation or ulceration when it does not exist thereby requiring endoscopy to confirm its presence, and further endoscopic assessment may still be required in patients with persistent symptoms despite apparent healing on MRE.

\section{Video capsule endoscopy}

Video capsule endoscopy (VCE) has a high sensitivity for detecting small bowel CD, and is currently offered to patients with a clinical suspicion for small bowel involvement with negative ileocolonoscopy and cross-sectional imaging. Recently it was demonstrated that using VCE as a third diagnostic test is not cost-effective, and therefore the optimal positioning of VCE as a diagnostic tool in $\mathrm{CD}$ remains unclear. ${ }^{70}$ Given the enhanced sensitivity over other small bowel imaging techniques, (Table 4) ${ }^{65,71,72}$ consideration has been given to using VCE as the first or second line diagnostic test for the assessment of MH. An initial prospective study of 40 patients with known or suspected non-stricturing nonpenetrating $\mathrm{CD}$ investigated the use of $\mathrm{VCE}$ for assessment of $\mathrm{MH}$ during an acute $\mathrm{CD}$ flare. ${ }^{73}$ Although the overall number of large ulcers as assessed by VCE decreased significantly in patents who responded to medical therapy (CDAI drop $>100$ points or CDAI $<150$ ), there was no significant change in the presence of other endoscopic lesions (apthous ulcers, erythema, edema). This led the investigators to conclude that clinical response did not correlate with small bowel healing, and that MH of the small bowel as assessed by VCE had no impact on clinical outcomes. In contrast, a more recent study by Shafran et al. ${ }^{74}$ demonstrated that in a cohort of $23 \mathrm{CD}$ patients treatment adjustments based on VCE findings resulted in enhanced clinical remission.

The most recent study to investigate the role of VCE in MH assessment prospectively enrolled 43 patients with small bowel CD who were initiating therapy with an immunosuppressant or TNF-antagonist. ${ }^{75,76}$ Mucosal disease activity was studied using the capsule endoscopy Crohn's disease activity index (CECDAI) at baseline, week 12, and week 52 , and clinical disease activity was assessed using C-reactive protein, fecal calprotectin, quality of life questionnaires, and the Harvey-Bradshaw index. At 12 weeks, a significant improvement in clinical disease activity was observed and $27 \%$ of patients had normalization of CECDAI $(<3.5 ; p<0.0005,95 \%$ confidence interval 0.12-0.15). At 52 weeks, $42 \%$ of patients had complete $\mathrm{MH}$ ( $\mathrm{p}<0.000195 \% \mathrm{CI}-0.62$ to -0.22$)$ with concordant clinical and biochemical responses. These findings suggest that $\mathrm{MH}$ of the small bowel is of clinical importance, and assessment by VCE is feasible.

Recently, a second generation VCE (PCCE2, Given Imaging Ltd.) was designed for the assessment of both small and large bowel disease activity. The extended battery life and enhanced visualization, with two cameras on either side of the capsule, might allow for a more robust evaluation of disease activity, thereby creating the potential for a non-invasive approach to assessing MH. The diagnostic accuracy of VCE for colonic inflammation has been investigated in UC patients, and the sensitivity (77\%), specificity (78\%), positive predictive value (81\%), and negative predictive value (74\%), was demonstrated to be only modest when compared to conventional endoscopy. ${ }^{77} \mathrm{In} \mathrm{CD}$, although a strong to moderate correlation between VCE and conventional endoscopy was found, VCE systematically underestimated severity of disease. Furthermore, the sensitivity and specificity for detecting 
colonic ulceration was only $86 \%$ and $40 \%$, respectively. ${ }^{78}$ Thus, the effectiveness of VCE for the assessment of $\mathrm{MH}$ should preferentially remain limited to small bowel $\mathrm{CD}$.

Other important limitations of VCE for the assessment of MH in CD are the risk of capsule retention and incomplete small bowel visualization. The overall rate of capsule retention in patients with suspected CD is reported to be only $2 \%,{ }^{79}$ but the rate can be as high as $13 \%$ in patients with confirmed $\mathrm{CD}$, and a substantial minority of these patients will require surgical resection of the retained device. ${ }^{80}$ In patients without capsule retention, the delayed small bowel transit time in CD results in the VCE not reaching the ileocecal valve prior to finishing recording in approximately $20 \%$ of patients. ${ }^{81-84}$ Even if a complete assessment of the small bowel is performed, the inability to obtain mucosal biopsies further limits VCE for assessing mucosal and histologic healing, and a sub-set of patients will require repeat testing with device assisted enteroscopy. ${ }^{85-89}$ Thus, the overall feasibility of using VCE for the routine assessment and monitoring of $\mathrm{MH}$ in $\mathrm{CD}$ is imperfect, and providers should limit its use to patients with known $\mathrm{CD}$ who have negative diagnostic imaging (MRE and/or ileocolonoscopy) and persistent symptoms despite changes in medical therapy.

\section{Device assisted enteroscopy}

Device assisted enteroscopy (DAE) encompasses several endoscopic techniques (singleballoon, double-balloon, and spiral enteroscopy) which allow for the direct visualization of small bowel mucosa. Currently, DAE is recommended for obtaining mucosal samples and assessing response to medical therapy in $\mathrm{CD}$ patients who are symptomatic, but ileocolonoscopy, VCE, and/or cross-sectional imaging are inconclusive for active disease. ${ }^{90}$ Another potential benefit for DAE is seen in patients with persistent lesions or small bowel obstruction refractory to medical therapy, where careful examination of the mucosa is required to rule out small bowel malignancy. The value of DAE beyond these indications is unclear, and the feasibility of utilizing DAE for the routine assessment of MH is yet to be examined.

\section{Integration into clinical practice: Identifying the optimal approach to assessing mucosal healing}

Multiple considerations influence the choice of a diagnostic test for evaluation of $\mathrm{MH}$. (Table 5, Figure 1) First, in patients with colonic or ileocolonic involvement, ileocolonoscopy remains the gold standard based upon its feasibility, ability to obtain mucosal biopsies, and high diagnostic accuracy. In patients with isolated small bowel disease beyond the reach of endoscopy, MRE will likely become the gold standard for disease monitoring. However MRE has a modest negative predictive value, and the presence of mucosal lesions cannot be reliably excluded based on this modality alone. In selected patients the use of VCE or DAE could be considered, with DAE being preferred in stricturing CD due to the risk of VCE retention. In patients where small bowel malignancy is a possibility, DAE is an ideal strategy. ${ }^{91-94}$ 


\section{Future directions: Surrogate markers for mucosal healing}

Although the potential value of MH based treatment algorithms seems clear, our currently available diagnostic tools are invasive, costly, and resource intensive. Accordingly, identification of surrogate markers for $\mathrm{MH}$ may facilitate the incorporation of $\mathrm{MH}$ as a clinical endpoint in practice. Of the various biomarkers currently under investigation, the fecal biomarkers (i.e. calprotectin) appear to be the most promising. The correlation between fecal biomarker concentrations and endoscopic disease activity in IBD is well established, and the sensitivity and specificity of these biomarkers for endoscopic remission and mucosal healing is relatively good. ${ }^{95-97}$ Furthermore, it has been demonstrated that fecal biomarkers may allow for the identification of histological disease activity in patients with clinical and endoscopic remission, ${ }^{98}$ which is not the case for other non-invasive diagnostic tools like MRE and VCE. Nevertheless, the optimum biomarker cut-off values for predicting MH have not been determined, and the value of these tests has not been definitively established for this purpose. Therefore, at the present time these biomarkers should not be considered valid surrogates for the gold standard of endoscopy.

\section{Conclusion}

Mucosal healing has become an important treatment target for the management of IBD. If this concept is to be successfully incorporated into management algorithms, providers must frequently assess $\mathrm{MH}$ and adjust therapeutic decisions accordingly. Although endoscopy is currently the gold standard for monitoring mucosal healing, several newer diagnostic tools are now available, and multiple considerations exist that determine the application of these diagnostics in this context. We have outlined a suggested algorithm for clinicians to follow in practice, and anticipate this will allow providers to better integrate mucosal healing as a clinical endpoint, thereby improving patient outcomes.

\section{Acknowledgements:}

Dr. Dulai is supported by the National Institute of Diabetes and Digestive and Kidney Diseases (Grant 5T32DK007202-39).

\section{REFERENCES}

1. Abraham C, Cho JH. Inflammatory bowel disease. N Engl J Med 2009;361:2066-78. [PubMed: 19923578]

2. Ordas I, Eckmann L, Talamini M, et al. Ulcerative colitis. Lancet 2012;380:1606-19. [PubMed: 22914296]

3. Baumgart DC, Sandborn WJ. Crohn's disease. Lancet 2012;380:1590-605. [PubMed: 22914295]

4. Williet N, Sandborn WJ, Peyrin-Biroulet L. Patient-reported outcomes as primary end points in clinical trials of inflammatory bowel disease. Clin Gastroenterol Hepatol 2014;12:1246-56.e6. [PubMed: 24534550]

5. Peyrin-Biroulet L, Reinisch W, Colombel JF, et al. Clinical disease activity, C-reactive protein normalisation and mucosal healing in Crohn's disease in the SONIC trial. Gut 2014;63:88-95. [PubMed: 23974954]

6. Levesque BG, Sandborn WJ, Ruel J, et al. Converging Goals of Treatment for Inflammatory Bowel Disease, from Clinical Trials and Practice. Gastroenterology 2014. 
7. D'Haens G, Sandborn WJ, Feagan BG, et al. A review of activity indices and efficacy end points for clinical trials of medical therapy in adults with ulcerative colitis. Gastroenterology 2007;132:76386. [PubMed: 17258735]

8. D’Haens GR, Fedorak R, Lemann M, et al. Endpoints for clinical trials evaluating disease modification and structural damage in adults with Crohn's disease. Inflamm Bowel Dis 2009;15:1599-604. [PubMed: 19653291]

9. Walsh A, Palmer R, Travis S. Mucosal healing as a target of therapy for colonic inflammatory bowel disease and methods to score disease activity. Gastrointest Endosc Clin N Am 2014;24:367-78. [PubMed: 24975528]

10. Fries W, Belvedere A, Vetrano S. Sealing the broken barrier in IBD: intestinal permeability, epithelial cells and junctions. Curr Drug Targets 2013;14:1460-70. [PubMed: 24060148]

11. Neurath MF, Travis SP. Mucosal healing in inflammatory bowel diseases: a systematic review. Gut 2012;61:1619-35. [PubMed: 22842618]

12. Khanna R, Bouguen G, Feagan BG, et al. A systematic review of measurement of endoscopic disease activity and mucosal healing in Crohn's disease: recommendations for clinical trial design. Inflamm Bowel Dis 2014;20:1850-61. [PubMed: 25029615]

13. Samaan MA, Mosli MH, Sandborn WJ, et al. A systematic review of the measurement of endoscopic healing in ulcerative colitis clinical trials: recommendations and implications for future research. Inflamm Bowel Dis 2014;20:1465-71. [PubMed: 24831558]

14. Salim SY, Soderholm JD. Importance of disrupted intestinal barrier in inflammatory bowel diseases. Inflamm Bowel Dis 2011;17:362-81. [PubMed: 20725949]

15. Henderson P, van Limbergen JE, Schwarze J, et al. Function of the intestinal epithelium and its dysregulation in inflammatory bowel disease. Inflamm Bowel Dis 2011;17:382-95. [PubMed: 20645321]

16. Froslie KF, Jahnsen J, Moum BA, et al. Mucosal healing in inflammatory bowel disease: results from a Norwegian population-based cohort. Gastroenterology 2007;133:412-22. [PubMed: 17681162]

17. Ardizzone S, Cassinotti A, Duca P, et al. Mucosal healing predicts late outcomes after the first course of corticosteroids for newly diagnosed ulcerative colitis. Clin Gastroenterol Hepatol 2011;9:483-489.e3. [PubMed: 21195796]

18. Colombel JF, Rutgeerts P, Reinisch W, et al. Early mucosal healing with infliximab is associated with improved long-term clinical outcomes in ulcerative colitis. Gastroenterology 2011;141:1194201. [PubMed: 21723220]

19. Schnitzler F, Fidder H, Ferrante M, et al. Mucosal healing predicts long-term outcome of maintenance therapy with infliximab in Crohn's disease. Inflamm Bowel Dis 2009;15:1295-301. [PubMed: 19340881]

20. Rutgeerts P, Diamond RH, Bala M, et al. Scheduled maintenance treatment with infliximab is superior to episodic treatment for the healing of mucosal ulceration associated with Crohn's disease. Gastrointest Endosc 2006;63:433-42; quiz 464. [PubMed: 16500392]

21. Rutter MD, Saunders BP, Wilkinson KH, et al. Cancer surveillance in longstanding ulcerative colitis: endoscopic appearances help predict cancer risk. Gut 2004;53:1813-6. [PubMed: 15542520]

22. Baert F, Moortgat L, Van Assche G, et al. Mucosal healing predicts sustained clinical remission in patients with early-stage Crohn's disease. Gastroenterology 2010;138:463-8; quiz e10-1. [PubMed: 19818785]

23. Ordas I, Rimola J, Rodriguez S, et al. Accuracy of magnetic resonance enterography in assessing response to therapy and mucosal healing in patients with Crohn's disease. Gastroenterology 2014;146:374-82.e1. [PubMed: 24177375]

24. Dave M, Loftus EV Jr., Mucosal healing in inflammatory bowel disease-a true paradigm of success? Gastroenterol Hepatol (N Y) 2012;8:29-38. [PubMed: 22347830]

25. Fefferman DS, Farrell RJ. Endoscopy in inflammatory bowel disease: indications, surveillance, and use in clinical practice. Clin Gastroenterol Hepatol 2005;3:11-24. [PubMed: 15645399]

26. Leighton JA, Shen B, Baron TH, et al. ASGE guideline: endoscopy in the diagnosis and treatment of inflammatory bowel disease. Gastrointest Endosc 2006;63:558-65. [PubMed: 16564852] 
27. Bouguen G, Levesque BG, Feagan BG, et al. Treat to Target: A Proposed New Paradigm for the Management of Crohn's Disease. Clin Gastroenterol Hepatol 2013.

28. Bouguen G, Levesque BG, Pola S, et al. Endoscopic assessment and treating to target increase the likelihood of mucosal healing in patients with Crohn's disease. Clin Gastroenterol Hepatol 2014;12:978-85. [PubMed: 24246770]

29. Bouguen G, Levesque BG, Pola S, et al. Feasibility of endoscopic assessment and treating to target to achieve mucosal healing in ulcerative colitis. Inflamm Bowel Dis 2014;20:231-9. [PubMed: 24351660]

30. Siegel CA, Marden SM, Kozlowski C, et al. Crohn's Disease Patients Report Their Definitions of "Rare" Adverse Events, Remission and the Importance of Mucosal Healing: A Quantitative and Qualitative Study of What Patients Really Think. Gastroenterology;140:S-141.

31. Makkar R, Bo S. Colonoscopic perforation in inflammatory bowel disease. Gastroenterol Hepatol (N Y) 2013;9:573-83. [PubMed: 24729766]

32. Dulai PS, Fisher ES, Rothstein RI. How may the transition to value-based payment influence gastroenterology: threat or opportunity? Clin Gastroenterol Hepatol 2012;10:609-11. [PubMed: 22624804]

33. Lichtenstein GR, Ramsey D, Rubin DT. Randomised clinical trial: delayed-release oral mesalazine $4.8 \mathrm{~g} /$ day vs. $2.4 \mathrm{~g}$ /day in endoscopic mucosal healing--ASCEND I and II combined analysis. Aliment Pharmacol Ther 2011;33:672-8. [PubMed: 21255059]

34. Sandborn WJ, Kamm MA, Lichtenstein GR, et al. MMX Multi Matrix System mesalazine for the induction of remission in patients with mild-to-moderate ulcerative colitis: a combined analysis of two randomized, double-blind, placebo-controlled trials. Aliment Pharmacol Ther 2007;26:20515. [PubMed: 17593066]

35. Gross V, Bar-Meir S, Lavy A, et al. Budesonide foam versus budesonide enema in active ulcerative proctitis and proctosigmoiditis. Aliment Pharmacol Ther 2006;23:303-12. [PubMed: 16393311]

36. Ardizzone S, Maconi G, Russo A, et al. Randomised controlled trial of azathioprine and 5aminosalicylic acid for treatment of steroid dependent ulcerative colitis. Gut 2006;55:47-53. [PubMed: 15972298]

37. Ogata H, Kato J, Hirai F, et al. Double-blind, placebo-controlled trial of oral tacrolimus (FK506) in the management of hospitalized patients with steroid-refractory ulcerative colitis. Inflamm Bowel Dis 2012;18:803-8. [PubMed: 21887732]

38. Sandborn WJ, Feagan BG, Marano C, et al. Subcutaneous golimumab maintains clinical response in patients with moderate-to-severe ulcerative colitis. Gastroenterology 2014;146:96-109.e1. [PubMed: 23770005]

39. Rutgeerts P, Sandborn WJ, Feagan BG, et al. Infliximab for induction and maintenance therapy for ulcerative colitis. N Engl J Med 2005;353:2462-76. [PubMed: 16339095]

40. Sandborn WJ, van Assche G, Reinisch W, et al. Adalimumab induces and maintains clinical remission in patients with moderate-to-severe ulcerative colitis. Gastroenterology 2012;142:25765.e1-3. [PubMed: 22062358]

41. Reinisch W, Sandborn WJ, Hommes DW, et al. Adalimumab for induction of clinical remission in moderately to severely active ulcerative colitis: results of a randomised controlled trial. Gut 2011;60:780-7. [PubMed: 21209123]

42. Feagan BG, Rutgeerts P, Sands BE, et al. Vedolizumab as induction and maintenance therapy for ulcerative colitis. N Engl J Med 2013;369:699-710. [PubMed: 23964932]

43. Panaccione R, Ghosh S, Middleton S, et al. Combination therapy with infliximab and azathioprine is superior to monotherapy with either agent in ulcerative colitis. Gastroenterology 2014;146:392400 e3. [PubMed: 24512909]

44. Modigliani R, Mary JY, Simon JF, et al. Clinical, biological, and endoscopic picture of attacks of Crohn's disease. Evolution on prednisolone. Groupe d'Etude Therapeutique des Affections Inflammatoires Digestives. Gastroenterology 1990;98:811-8. [PubMed: 2179031]

45. Mantzaris GJ, Christidou A, Sfakianakis M, et al. Azathioprine is superior to budesonide in achieving and maintaining mucosal healing and histologic remission in steroid-dependent Crohn's disease. Inflamm Bowel Dis 2009;15:375-82. [PubMed: 19009634] 
46. Rutgeerts P, Van Assche G, Sandborn WJ, et al. Adalimumab induces and maintains mucosal healing in patients with Crohn's disease: data from the EXTEND trial. Gastroenterology 2012;142:1102-1111.e2. [PubMed: 22326435]

47. Colombel JF, Sandborn WJ, Allez M, et al. Association between plasma concentrations of certolizumab pegol and endoscopic outcomes of patients with Crohn's disease. Clin Gastroenterol Hepatol 2014;12:423-31.e1. [PubMed: 24184736]

48. Colombel JF, Sandborn WJ, Reinisch W, et al. Infliximab, azathioprine, or combination therapy for Crohn's disease. N Engl J Med 2010;362:1383-95. [PubMed: 20393175]

49. Feagan B Enhanced Algorithm for Crohn's Treatment Incorporating Early Combination Therapy (REACT2). ClinicalTrials.gov.

50. Walsh AJ, Ghosh A, Brain AO, et al. Comparing disease activity indices in ulcerative colitis. J Crohns Colitis 2014;8:318-25. [PubMed: 24120021]

51. Feagan BG, Sandborn WJ, D'Haens G, et al. The role of centralized reading of endoscopy in a randomized controlled trial of mesalamine for ulcerative colitis. Gastroenterology 2013;145:149157.e2. [PubMed: 23528626]

52. Bryant RV, Winer S, Spl T, et al. Systematic review: Histological remission in inflammatory bowel disease. Is 'complete' remission the new treatment paradigm? An IOIBD initiative. J Crohns Colitis 2014.

53. Mosli MH, Feagan BG, Sandborn WJ, et al. Histologic evaluation of ulcerative colitis: a systematic review of disease activity indices. Inflamm Bowel Dis 2014;20:564-75. [PubMed: 24412993]

54. Mosli MH, Feagan BG, Zou G, et al. Reproducibility of histological assessments of disease activity in UC. Gut 2014.

55. Tontini GE, Vecchi M, Neurath MF, et al. Advanced endoscopic imaging techniques in Crohn's disease. J Crohns Colitis 2014;8:261-9. [PubMed: 24080247]

56. Tontini GE, Vecchi M, Neurath MF, et al. Review article: newer optical and digital chromoendoscopy techniques vs. dye-based chromoendoscopy for diagnosis and surveillance in inflammatory bowel disease. Aliment Pharmacol Ther 2013;38:1198-208. [PubMed: 24117471]

57. Koutroubakis IE, Tsiolakidou G, Karmiris K, et al. Role of angiogenesis in inflammatory bowel disease. Inflamm Bowel Dis 2006;12:515-23. [PubMed: 16775497]

58. Pellise M, Lopez-Ceron M, Rodriguez de Miguel C, et al. Narrow-band imaging as an alternative to chromoendoscopy for the detection of dysplasia in long-standing inflammatory bowel disease: a prospective, randomized, crossover study. Gastrointest Endosc 2011;74:840-8. [PubMed: 21802681]

59. Danese S, Fiorino G, Angelucci E, et al. Narrow-band imaging endoscopy to assess mucosal angiogenesis in inflammatory bowel disease: a pilot study. World J Gastroenterol 2010;16:2396400. [PubMed: 20480525]

60. Kudo T, Matsumoto T, Esaki M, et al. Mucosal vascular pattern in ulcerative colitis: observations using narrow band imaging colonoscopy with special reference to histologic inflammation. Int $\mathbf{J}$ Colorectal Dis 2009;24:495-501. [PubMed: 19145441]

61. Neumann H, Vieth M, Gunther C, et al. Virtual chromoendoscopy for prediction of severity and disease extent in patients with inflammatory bowel disease: a randomized controlled study. Inflamm Bowel Dis 2013;19:1935-42. [PubMed: 23839228]

62. Villanacci V, Antonelli E, Geboes K, et al. Histological healing in inflammatory bowel disease: a still unfulfilled promise. World J Gastroenterol 2013;19:968-78. [PubMed: 23467585]

63. Peyrin-Biroulet L, Loftus EV Jr., Colombel JF, et al. The natural history of adult Crohn's disease in population-based cohorts. Am J Gastroenterol 2010;105:289-97. [PubMed: 19861953]

64. Papay P, Ignjatovic A, Karmiris K, et al. Optimising monitoring in the management of Crohn's disease: a physician's perspective. J Crohns Colitis 2013;7:653-69. [PubMed: 23562672]

65. Qiu Y, Mao R, Chen BL, et al. Systematic review with meta-analysis: magnetic resonance enterography vs. computed tomography enterography for evaluating disease activity in small bowel Crohn's disease. Aliment Pharmacol Ther 2014;40:134-46. [PubMed: 24912799]

66. Cipriano LE, Levesque BG, Zaric GS, et al. Cost-effectiveness of imaging strategies to reduce radiation-induced cancer risk in Crohn's disease. Inflamm Bowel Dis 2012;18:1240-8. [PubMed: 21928375] 
67. Madsen SM, Thomsen HS, Schlichting P, et al. Evaluation of treatment response in active Crohn's disease by low-field magnetic resonance imaging. Abdom Imaging 1999;24:232-9. [PubMed: 10227885]

68. Van Assche G, Herrmann KA, Louis E, et al. Effects of infliximab therapy on transmural lesions as assessed by magnetic resonance enteroclysis in patients with ileal Crohn's disease. J Crohns Colitis 2013;7:950-7. [PubMed: 23411006]

69. Rimola J, Rodriguez S, Garcia-Bosch O, et al. Magnetic resonance for assessment of disease activity and severity in ileocolonic Crohn's disease. Gut 2009;58:1113-20. [PubMed: 19136510]

70. Levesque BG, Cipriano LE, Chang SL, et al. Cost effectiveness of alternative imaging strategies for the diagnosis of small-bowel Crohn's disease. Clin Gastroenterol Hepatol 2010;8:261-7, 267 e1-4. [PubMed: 19896559]

71. Triester SL, Leighton JA, Leontiadis GI, et al. A meta-analysis of the yield of capsule endoscopy compared to other diagnostic modalities in patients with non-stricturing small bowel Crohn's disease. Am J Gastroenterol 2006;101:954-64. [PubMed: 16696781]

72. Dionisio PM, Gurudu SR, Leighton JA, et al. Capsule endoscopy has a significantly higher diagnostic yield in patients with suspected and established small-bowel Crohn's disease: a metaanalysis. Am J Gastroenterol 2010;105:1240-8; quiz 1249. [PubMed: 20029412]

73. Efthymiou A, Viazis N, Mantzaris G, et al. Does clinical response correlate with mucosal healing in patients with Crohn's disease of the small bowel? A prospective, case-series study using wireless capsule endoscopy. Inflamm Bowel Dis 2008;14:1542-7. [PubMed: 18521929]

74. Shafran I, Burgunder P, Kwa M. P-081 The Use of Serial Wireless Capsule Endoscopy in Treatment Decisions to Improve Outcomes in Small Bowel Crohn's Disease. Inflammatory Bowel Diseases 2013;19:S58 10.1097/01.MIB.0000438760.14555.c4.

75. Hall B, Holleran G, Chin JL, et al. A prospective 52week mucosal healing assessment of small bowel Crohn's disease as detected by capsule endoscopy. J Crohns Colitis 2014.

76. Hall BJ, Holleran GE, Smith SM, et al. A prospective 12-week mucosal healing assessment of small bowel Crohn's disease as detected by capsule endoscopy. Eur J Gastroenterol Hepatol 2014;26:1253-9. [PubMed: 25264865]

77. Riccioni ME, Urgesi R, Cianci R, et al. Colon capsule endoscopy: Advantages, limitations and expectations. Which novelties? World J Gastrointest Endosc 2012;4:99-107. [PubMed: 22523610]

78. D'Haens GR, Franchimont D, Lowenberg M, et al. Tu1531 Assessment of the Performance of the Colonic PillCam Pcce-2 in Patients With Active Crohn's Disease: a Pilot Study. Gastrointestinal Endoscopy;79:AB574.

79. Hudesman D, Mazurek J, Swaminath A. Capsule endoscopy in Crohn's disease: Are we seeing any better? World J Gastroenterol 2014;20:13044-13051. [PubMed: 25278698]

80. Cheifetz AS, Kornbluth AA, Legnani P, et al. The risk of retention of the capsule endoscope in patients with known or suspected Crohn's disease. Am J Gastroenterol 2006;101:2218-22. [PubMed: 16848804]

81. Liao Z, Gao R, Xu C, et al. Indications and detection, completion, and retention rates of smallbowel capsule endoscopy: a systematic review. Gastrointest Endosc 2010;71:280-6. [PubMed: 20152309]

82. Niv E, Fishman S, Kachman H, et al. Sequential capsule endoscopy of the small bowel for followup of patients with known Crohn's disease. J Crohns Colitis 2014.

83. Rondonotti E, Herrerias JM, Pennazio M, et al. Complications, limitations, and failures of capsule endoscopy: a review of 733 cases. Gastrointestinal endoscopy 2005;62:712-6; quiz 752, 754. [PubMed: 16246685]

84. Liao Z, Gao R, Xu C, et al. Indications and detection, completion, and retention rates of smallbowel capsule endoscopy: a systematic review. Gastrointestinal endoscopy 2010;71:280-6. [PubMed: 20152309]

85. Cahill C, Gordon PH, Petrucci A, et al. Small bowel adenocarcinoma and Crohn's disease: Any further ahead than 50 years ago? World J Gastroenterol 2014;20:11486-11495. [PubMed: 25206256] 
86. Goldstein JL, Eisen GM, Lewis B, et al. Small bowel mucosal injury is reduced in healthy subjects treated with celecoxib compared with ibuprofen plus omeprazole, as assessed by video capsule endoscopy. Alimentary pharmacology \& therapeutics 2007;25:1211-22. [PubMed: 17451567]

87. Maiden L, Thjodleifsson B, Theodors A, et al. A quantitative analysis of NSAID-induced small bowel pathology by capsule enteroscopy. Gastroenterology 2005;128:1172-8. [PubMed: 15887101]

88. Goldstein JL, Eisen GM, Lewis B, et al. Video capsule endoscopy to prospectively assess small bowel injury with celecoxib, naproxen plus omeprazole, and placebo. Clinical gastroenterology and hepatology : the official clinical practice journal of the American Gastroenterological Association 2005;3:133-41. [PubMed: 15704047]

89. Graham DY, Opekun AR, Willingham FF, et al. Visible small-intestinal mucosal injury in chronic NSAID users. Clinical gastroenterology and hepatology : the official clinical practice journal of the American Gastroenterological Association 2005;3:55-9. [PubMed: 15645405]

90. Eliakim R, Carter D. Endoscopic assessment of the small bowel. Digestive diseases 2013;31:1948. [PubMed: 24030224]

91. Lewis BS, Eisen GM, Friedman S. A pooled analysis to evaluate results of capsule endoscopy trials. Endoscopy 2005;37:960-5. [PubMed: 16189768]

92. Ross A, Mehdizadeh S, Tokar J, et al. Double balloon enteroscopy detects small bowel mass lesions missed by capsule endoscopy. Digestive diseases and sciences 2008;53:2140-3. [PubMed: 18270840]

93. Schwartz GD, Barkin JS. Small-bowel tumors detected by wireless capsule endoscopy. Digestive diseases and sciences 2007;52:1026-30. [PubMed: 17380403]

94. Cangemi DJ, Patel MK, Gomez V, et al. Small bowel tumors discovered during double-balloon enteroscopy: analysis of a large prospectively collected single-center database. Journal of clinical gastroenterology 2013;47:769-72. [PubMed: 23426457]

95. Wright EK, De Cruz P, Gearry R, et al. Fecal biomarkers in the diagnosis and monitoring of Crohn's disease. Inflamm Bowel Dis 2014;20:1668-77. [PubMed: 24918319]

96. Yang Z, Clark N, Park KT. Effectiveness and cost-effectiveness of measuring fecal calprotectin in diagnosis of inflammatory bowel disease in adults and children. Clin Gastroenterol Hepatol 2014;12:253-62.e2. [PubMed: 23883663]

97. D'Haens G, Ferrante M, Vermeire S, et al. Fecal calprotectin is a surrogate marker for endoscopic lesions in inflammatory bowel disease. Inflamm Bowel Dis 2012;18:2218-24. [PubMed: 22344983]

98. Guardiola J, Lobaton T, Rodriguez-Alonso L, et al. Fecal Level of Calprotectin Identifies Histologic Inflammation in Patients With Ulcerative Colitis in Clinical and Endoscopic Remission. Clin Gastroenterol Hepatol 2014.

99. Samuel S, Bruining DH, Loftus EV Jr., et al. Validation of the ulcerative colitis colonoscopic index of severity and its correlation with disease activity measures. Clin Gastroenterol Hepatol 2013;11:49-54.e1. [PubMed: 22902762] 


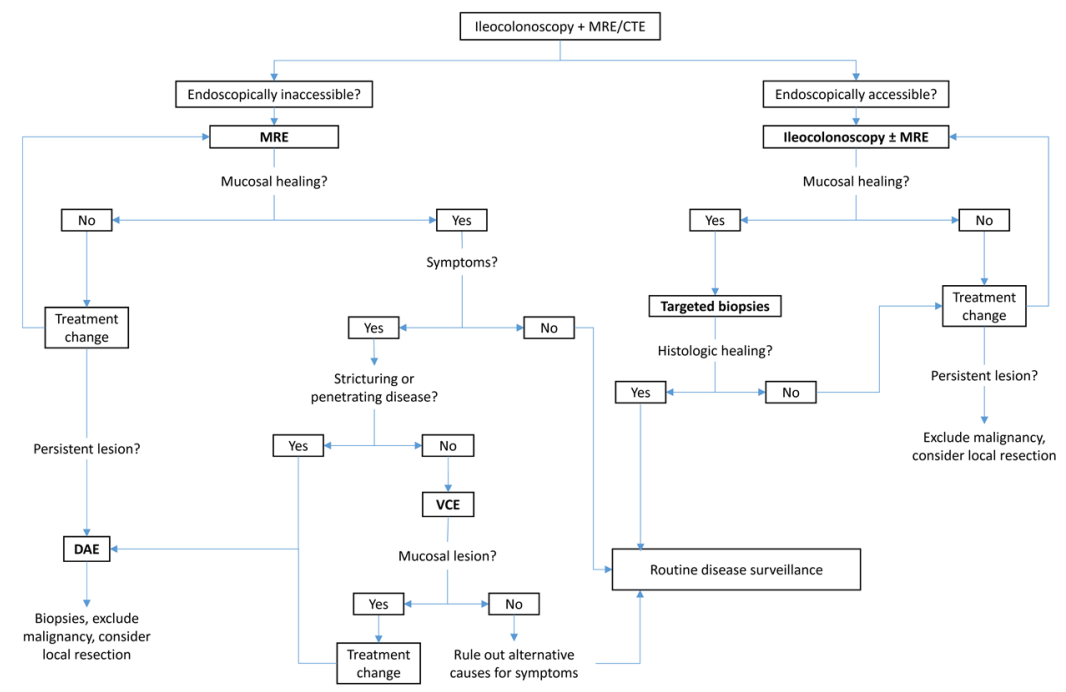

Figure 1.

Approach to assessing mucosal healing in clinical practice MRE - magnetic resonance enterography; CTE - computerized tomography enterography; DAE - device assisted enteroscopy; VCE - video capsule endoscopy

Persistent lesion is defined as one that remains identifiable despite significant changes in treatment and an objective clinical improvement in disease activity. 
Table 1.

Benefits of improving endoscopic disease activity and achieving mucosal healing ${ }^{16-22}$

\begin{tabular}{|ll|}
\hline - & Sustained clinical remission \\
- & Reduction in steroid and immunosuppressive use \\
- & Decreased hospitalization rates \\
- & Reduction in colectomy and surgical resection \\
\hline
\end{tabular}


Table 2.

Mucosal healing as an endpoint in clinical trials $5,33-48$

\begin{tabular}{|c|c|c|c|}
\hline & Drug & Definition of mucosal healing & Rates achieved \\
\hline \multicolumn{4}{|l|}{ Ulcerative Colitis } \\
\hline Lichtenstein et al. ${ }^{33}$ & Mesalamine & Mayo endoscopic sub-score of 0 or 1 & 70 and $80 \%$ \\
\hline Sandborn et al. ${ }^{34}$ & Mesalamine & $\begin{array}{l}\text { Modified Sutherland } \\
\text { sigmoidoscopy score of } 0\end{array}$ & $32 \%$ \\
\hline Gross et al. ${ }^{35}$ & Budesonide & Rachmilewitz index $<4$ & 52 and $54 \%$ \\
\hline Ardizzone et al. ${ }^{36}$ & Azathioprine & Baron index score of 0 or 1 & $53 \%$ \\
\hline Ogata et al. ${ }^{37}$ & Tacrolimus & $\begin{array}{l}\text { Mayo + Sutherland } \\
\text { endoscopic score of } 0 \text { or } 1\end{array}$ & $44 \%$ \\
\hline $\begin{array}{l}\text { Sandborn et al. }{ }^{5,38} \\
\text { Rutgeerts et al. }{ }^{39} \\
\text { Sandborn et al. }{ }^{40} \\
\text { Reinisch et al. }{ }^{41} \\
\text { Feagan et al. }{ }^{42}\end{array}$ & Biologics & Mayo endoscopic sub-score of 0 or 1 & $25-60 \%$ \\
\hline Panaccione et al. ${ }^{43}$ & $\begin{array}{l}\text { Infliximab } \pm \\
\text { Azathioprine }\end{array}$ & Mayo endoscopic sub-score of 0 or 1 & $37-63 \%$ \\
\hline \multicolumn{4}{|l|}{ Crohn's disease } \\
\hline Modigliani et al. ${ }^{44}$ & Prednisone & CDEIS no lesions or scars & $13 \%$ \\
\hline Mantzaris et al. ${ }^{45}$ & Azathioprine & $\begin{array}{l}\text { CDEIS complete mucosal healing (disappearance of all pathologic } \\
\text { findings) and near-complete healing (occasional aphthae, residual } \\
\text { superficial erosions, thickened folds) }\end{array}$ & 25 and $83 \%$ \\
\hline $\begin{array}{l}\text { Rutgeerts et al. }{ }^{46} \\
\text { Colombel et al. }{ }^{47}\end{array}$ & Biologics & $\begin{array}{l}\text { SES-CD absence of mucosal ulceration } \\
\text { CDEIS < } 3 \text { (endoscopic remission) }\end{array}$ & $\begin{array}{l}24-27 \% \\
13-19 \%\end{array}$ \\
\hline Colombel et al. ${ }^{48}$ & $\begin{array}{l}\text { Infliximab + } \\
\text { Azathioprine }\end{array}$ & Complete absence of ulceration & $17-44 \%$ \\
\hline
\end{tabular}

CDEIS - Crohn's disease endoscopic index of severity; SES-CD - simplified endoscopic score for Crohn's disease. 
Table 3.

Endoscopy based disease activity indices in inflammatory bowel disease $\mathrm{e}^{12,13,50,99}$

\begin{tabular}{|c|c|c|c|}
\hline Index & Scoring & Agreement among readers & Comments \\
\hline \multicolumn{4}{|c|}{ Ulcerative Colitis } \\
\hline Mayo score & $\begin{array}{l}\text { Step-wise } 4 \text { grade scale based on vascular pattern, } \\
\text { erythema, friability, erosions, ulcerations and } \\
\text { bleeding }\end{array}$ & $\begin{array}{l}\text { Interobserver: Kappa } 0.38 \\
95 \% \text { CI } 0.33-0.43\end{array}$ & $\begin{array}{l}\text { Ease of administration } \\
\text { Widely used } \\
\text { Not validated }\end{array}$ \\
\hline UCEIS & $\begin{array}{l}\text { Numeric grading of sub-scores for vascular pattern, } \\
\text { bleeding, and erosions/ulcerations }\end{array}$ & $\begin{array}{l}\text { Interobserver: Kappa } 0.50 \\
95 \% \text { CI } 0.49-0.52\end{array}$ & $\begin{array}{l}\text { New index } \\
\text { Not widely used } \\
\text { Partially validated }\end{array}$ \\
\hline \multicolumn{4}{|c|}{ Crohn's Disease } \\
\hline CDEIS & $\begin{array}{l}\text { Numerical grading } \\
(0-44 \text { points }) \text { based on variables related to } \\
\text { ulcerations, area of involvement, and stenosis } \\
\text { characteristics in colon and TI }\end{array}$ & $\begin{array}{l}\text { Intraobserver: ICC } 0.89 \\
95 \% \text { CI } 0.86-0.93 \\
\text { Interobserver: ICC } 0.71 \\
95 \% \text { CI } 0.61-0.79\end{array}$ & $\begin{array}{l}\text { Detailed assessment, accounts for global } \\
\text { disease (concerns regarding feasibility of } \\
\text { use in practice) } \\
\text { Partially validated } \\
\text { poor agreement for ulcers }\end{array}$ \\
\hline SES-CD & $\begin{array}{l}\text { Numerical grading } \\
\text { ( } 0-56 \text { points) based on variables related to size of } \\
\text { ulcer, degree of ulcerated surface, affected surface, } \\
\text { or presence of narrowing throughout the colon/TI }\end{array}$ & $\begin{array}{l}\text { Intraobserver: ICC } 0.91 \\
95 \% \text { CI } 0.87-0.94 \\
\text { Interobserver: ICC } 0.83 \\
95 \% \text { CI, } 0.75-0.89\end{array}$ & $\begin{array}{l}\text { Simplified version of CDEIS } \\
\text { Partially validated } \\
\text { High degree of correlation with CDEIS } \\
\text { for grading and responsiveness to } \\
\text { changes }\end{array}$ \\
\hline
\end{tabular}

Kappa values categorized as: poor $(<0.2)$; fair $(0.21-0.4)$; moderate $(0.41-0.6)$; good $(0.61-0.8)$, and very good agreement $(0.81-1.0)$. Concordance correlation coefficient (CCC) categorized as: excellent (0.81-1.00), good (0.61-0.80), moderate (0.41-0.60), and fair agreement (0.21-0.40). UCEIS - Ulcerative colitis endoscopic index of severity; CDEIS - Crohn's disease endoscopic index of severity; SES-CD - Simplified endoscopic score in Crohn's disease; TI - terminal ileum 
Table 4.

Comparative effectiveness of diagnostics in small bowel Crohn's disease ${ }^{65,71,72}$

\begin{tabular}{|l|l|l|l|}
\hline & $\begin{array}{l}\text { Overall IY } \\
\text { (95\% CI) }\end{array}$ & $\begin{array}{l}\text { Suspected CD IY } \\
\text { (95\% CI) }\end{array}$ & $\begin{array}{l}\text { Established CD IY } \\
\text { (95\% CI) }\end{array}$ \\
\hline VCE vs. SBR & $37 \%(29$ to 45$)$ & $32 \%(16$ to 48$)$ & $38 \%(22$ to 54$)$ \\
\hline VCE vs. PE & $42 \%(31$ to 53$)$ & $18 \%(-23$ to 59$)$ & $57 \%(43$ to 71$)$ \\
\hline VCE vs. CTE & $39 \%(27$ to 50$)$ & $47 \%(31$ to 63$)$ & $32 \%(16$ to 47$)$ \\
\hline VCE vs. MRE & $7 \%(-4$ to 17$)$ & $10 \%(-14$ to 34$)$ & $-6 \%(-30$ to 19$)$ \\
\hline MRE vs. CTE & $4 \%(-4$ to 12$)$ & - & - \\
\hline
\end{tabular}

IY - incremental yield, CTE - computerized tomography enterography; MRE - magnetic resonance enterography; SBR - small bowel radiography; $\mathrm{PE}$ - push enteroscopy 
Table 5.

Advantages and disadvantages to current diagnostics for mucosal healing assessment

\begin{tabular}{|l|l|l|}
\hline & Advantages & Disadvantages \\
\hline Endoscopy & $\begin{array}{l}\text { High sensitivity and specificity } \\
\text { Histological assessment } \\
\text { Management of complications } \\
\text { (i.e. strictures) }\end{array}$ & $\begin{array}{l}\text { Invasive } \\
\text { Only for ileocolonic disease }\end{array}$ \\
\hline MRE & $\begin{array}{l}\text { Non-invasive } \\
\text { small } \pm \text { large bowel assessment } \\
\text { identification of intra- and extra-luminal complications }\end{array}$ & $\begin{array}{l}\text { Low specificity and NPV } \\
\text { No histological assessment } \\
\text { Unclear cost-effectiveness }\end{array}$ \\
\hline VCE & $\begin{array}{l}\text { Non-invasive } \\
\text { Highly sensitive }\end{array}$ & $\begin{array}{l}\text { Modest specificity } \\
\text { Retention and incompletion rate } \\
\text { No histological assessment } \\
\text { Under estimate colonic severity } \\
\text { Time consuming } \\
\text { Not cost-effective }\end{array}$ \\
\hline DAE & $\begin{array}{l}\text { Visualization of small bowel } \\
\text { Management of complications (i.e. strictures, VCE } \\
\text { retention) }\end{array}$ & $\begin{array}{l}\text { Invasiveness and complications } \\
\text { Extra training and time consuming } \\
\text { Utility limited to assessing persistent lesions despite medical therapy }\end{array}$ \\
\hline
\end{tabular}

MRE - magnetic resonance enterography; NPV - negative predictive value; VCE - video capsule endoscopy; DAE - device assisted enteroscopy 